(2) Open Access Full Text Article

\title{
Cytomegalovirus retinitis treated with valganciclovir in Wegener's granulomatosis
}

This article was published in the following Dove Press journal:

Clinical Ophthalmology

26 March 2012

Number of times this article has been viewed

\section{Yoshiaki Kabata' \\ Genichiro Takahashi' \\ Hiroshi Tsuneoka ${ }^{2}$ \\ 'Department of Ophthalmology, Jikei University School of Medicine, Katsushika Medical Center, Katsushika, Tokyo, Japan; ${ }^{2}$ Department of Ophthalmology, Jikei University School of Medicine, Minato, Tokyo, Japan}

Correspondence: Yoshiaki Kabata Department of Ophthalmology, jikei University School of Medicine, Katsushika Medical Center, 6-4I-2 Aoto, Katsushika, Tokyo I25-8506, Japan

Tel +81336032 III

$\mathrm{Fax}+81336022839$

Email kabata22I22@gmail.com

\begin{abstract}
A case of cytomegalovirus (CMV) retinitis in a patient with Wegener's granulomatosis treated with oral valganciclovir as maintenance therapy is reported. A 68-year-old male patient with anti-proteinase-3 ANCA-positive Wegener's granulomatosis who was receiving immunosuppressive therapy with methylprednisolone, cyclophosphamide, and azathioprine developed CMV retinitis. The patient received intravenous ganciclovir as induction therapy and oral valganciclovir as maintenance therapy. The patient responded to treatment and showed no recurrence for 8 months. There were no serious adverse effects associated with oral valganciclovir. Oral valganciclovir is convenient and effective for the management of CMV retinitis in the patient with Wegener's granulomatosis.
\end{abstract}

Keywords: cytomegalovirus retinitis, Wegener's granulomatosis, valganciclovir, ganciclovir, maintenance therapy

\section{Introduction}

Cytomegalovirus (CMV) retinitis is an opportunistic infection in patients with acquired immunodeficiency syndrome who are receiving immunosuppressive therapy, which causes progressive retinal destruction or retinal detachment with severe visual impairment, and affects quality of life. ${ }^{1-3}$ The primary treatment for CMV retinitis is intravenous ganciclovir. In recent years, oral valganciclovir has been reported as being as effective as intravenous ganciclovir and is convenient for the long-term management of CMV retinitis in patients with acquired immunodeficiency syndrome. ${ }^{3}$

CMV retinitis in patients with Wegener's granulomatosis is rare. ${ }^{4}$ Therefore, therapeutic reporting on CMV retinitis in Wegener's granulomatosis is inadequate. ${ }^{5-7}$ To our knowledge, there have been no previous reports on oral valganciclovir therapy for CMV retinitis in Wegener's granulomatosis.

We report a case of CMV retinitis in a patient with Wegener's granulomatosis treated with intravenous ganciclovir as induction therapy and oral valganciclovir as maintenance therapy.

\section{Case report}

A 68-year-old man presented to the Department of Ophthalmology, Jikei University of Medicine, Katushika Medical Center complaining of vision loss in his right eye for the previous month. The patient had been diagnosed with anti-proteinase-3 ANCApositive Wegener's granulomatosis eight years previously, and was receiving immunosuppressive therapy with methylprednisolone, cyclophosphamide, and azathioprine. 
He developed glomerulonephritis, rhinitis, pulmonary nodules as coin lesions, and nodules on the elbow. His right vision was finger counting 1 per meter and left vision was $20 / 20$. There were grade $2+$ cells in his right anterior chamber. His left anterior chamber was normal. On fundus examination, the right eye showed yellowish-white retinitis surrounding the inferior and temporal aspect of the macula and along the superior vascular arcades as typical changes of CMV retinitis, angiostenosis of the inferior vascular arcades, and retinal hemorrhage (Figure 1). Retinal hemorrhage was observed around the inferior and temporal aspect of the macula in the left eye. Polymerase chain reaction of the aqueous sample was positive for CMV retinitis and negative for herpes simplex virus, herpes zoster virus, and toxoplasmosis. From these clinical findings, the laboratory results, and treatment with immunosuppressive therapy, we diagnosed CMV retinitis.

After providing informed consent, the patient received intravenous ganciclovir $5 \mathrm{mg} / \mathrm{kg}$ twice a day for 25 days as induction therapy with monitoring of retinitis, followed by oral valganciclovir $900 \mathrm{mg}$ once a day as maintenance therapy. At 1 month from onset, there was no further progression of retinitis. Three months afterwards, development of retinal pigment epithelial changes and reduction of retinal hemorrhage were observed in the right eye (Figure 2). Reduction of retinal hemorrhage was also observed in the left eye. Oral valganciclovir therapy was continued because of continuation of immunosuppressive therapy. Transient diarrhea developed as an adverse effect associated with valganciclovir. There was

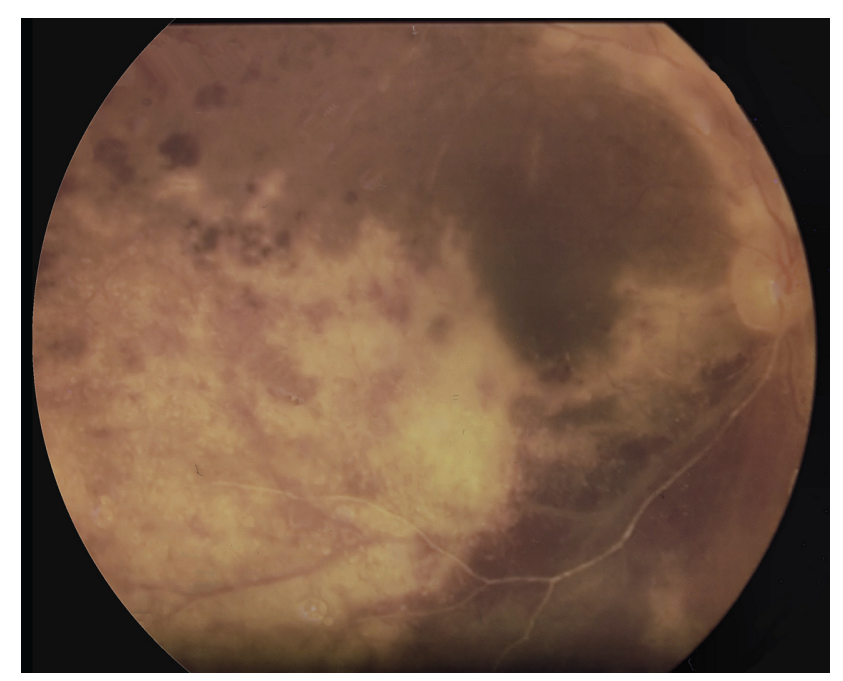

Figure I The right eye showed yellowish-white retinitis surrounding the inferior and temporal aspect of the macula and along the superior vascular arcades, angiostenosis of the inferior vascular arcades, and retinal hemorrhage.

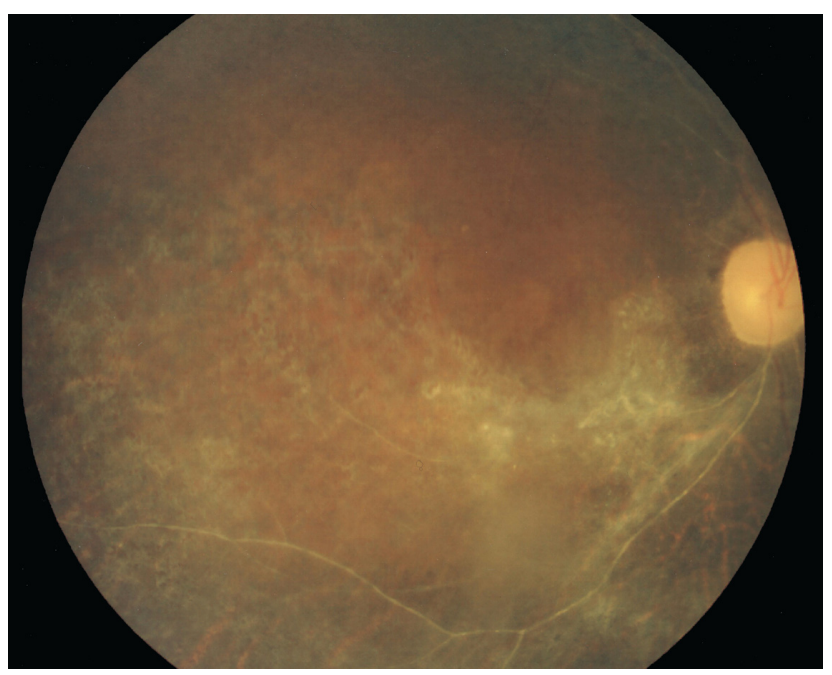

Figure 2 After treatment, development of retinal pigment epithelial changes and reduction of retinal hemorrhage were observed in the right eye.

no recurrence of retinitis after 8 months, but visual acuity was not improved.

\section{Discussion}

Valganciclovir is an orally administered prodrug that is rapidly hydrolyzed to ganciclovir, the active compound. ${ }^{8,9}$ The absolute bioavailability of ganciclovir from valganciclovir is $60 \%,{ }^{10}$ and a dose of $900 \mathrm{mg}$ results in ganciclovir blood levels similar to those obtained using an intravenous ganciclovir dose of $5 \mathrm{mg} / \mathrm{kg}$ body weight. ${ }^{11}$ Adverse effects associated with valganciclovir include pancytopenia, nausea, vomiting, diarrhea, peripheral neuropathy, seizures, and confusion. ${ }^{9}$ This patient developed only transient diarrhea. Pancytopenia was not present on the basis of blood test results.

Maintenance therapy is needed for patients receiving immunosuppressive therapy. Previously, the only treatment for cytomegalovirus retinitis was via the intravenous route, so patients are at risk of catheter-related complications. ${ }^{1}$ Oral valganciclovir can reduce the risk of catheter-related complications in particular infections, which is beneficial for patients with Wegener's granulomatosis. ${ }^{3}$

Wegener's granulomatosis causes a variety of ophthalmic symptoms, ${ }^{12}$ but the development of CMV retinitis is rare. ${ }^{4}$ According to previous reports of CMV retinitis in Wegener's granulomatosis, intravenous ganciclovir and intravitreal implant treatment have been described. ${ }^{5-7}$ The ganciclovir implant is more effective than intravenous ganciclovir, but patients treated with a ganciclovir implant alone remain at greater risk for the development of cytomegalovirus disease outside of the treated eye. ${ }^{2}$ 
Therefore, a ganciclovir implant is administered; it is done in combination with intravenous ganciclovir or oral valganciclovir. ${ }^{8}$ There are risks of complications associated with implant insertion, ${ }^{2,13}$ so ganciclovir implant adaptation should be carefully considered.

In this patient, we selected intravenous ganciclovir as the initial treatment given the involvement of both eyes, the severity of CMV retinitis, and his general condition, followed by oral valganciclovir as maintenance treatment, and achieved a remission. From this time forward, we will consider alternative treatments, ie, a ganciclovir intravitreal implant, intravenous foscarnet, and intravenous cidofovir, ${ }^{8}$ according to the patient's condition.

\section{Conclusion}

We report a case of CMV retinitis in a patient with Wegener's granulomatosis treated with intravenous ganciclovir as induction therapy and oral valganciclovir as maintenance therapy. There were no serious adverse effects associated with oral valganciclovir, which was convenient and effective for the management of CMV retinitis in a patient with Wegener's granulomatosis. In the future, use of oral valganciclovir for the treatment of CMV retinitis in Wegener's granulomatosis is likely to increase.

\section{Acknowledgments}

The authors are grateful to Keita Hirano and the staff of the Department of Internal Medicine, Jikei University School of Medicine, Katushika Medical Center.

\section{Disclosure}

The authors have no proprietary or commercial interest in any of the materials discussed in this work.

\section{References}

1. Spector SA, McKinley GF, Lalezari JP, et al. Oral ganciclovir for the prevention of cytomegalovirus disease in persons with AIDS. Roche Cooperative Oral Ganciclovir Study Group. N Engl J Med. 1996; 334(23):1491-1497.

2. Musch DC, Martin DF, Gordon JF, Davis MD, Kuppermann BD. Treatment of cytomegalovirus retinitis with a sustained-release ganciclovir implant. The Ganciclovir Implant Study Group. N Engl J Med. 1997;337(2):83-90.

3. Martin DF, Sierra-Madero J, Walmsley S, et al. A controlled trial of valganciclovir as induction therapy for cytomegalovirus retinitis. N Engl J Med. 2002;346(15):1119-1126.

4. Charlier C, Henegar C, Launay O, et al. Risk factors for major infections in Wegener granulomatosis: analysis of 113 patients. Ann Rheum Dis. 2009;68(5):658-663.

5. Tanihara H, Nakayama Y, Honda Y. Wegener's granulomatosis with rapidly progressive retinitis and anterior uveitis. Acta Ophthalmol (Copenh). 1993;71(6):853-855.

6. Tugal-Tutkun I, Kir N, Gul A, Konice M, Urgancioglu M. Cytomegalovirus retinitis in a patient with Wegener's granulomatosis. Ophthalmologica. 2000;214(2):149-152.

7. Tranos PG, Georgalas I, Founti P, Ladas I. Cytomegalovirus retinitis presenting as vasculitis in a patient with Wegener's granulomatosis Clin Ophthalmol. 2008;2(4):961-963.

8. Patil AJ, Sharma A, Kenney MC, Kuppermann BD. Valganciclovir in the treatment of cytomegalovirus retinitis in HIV-infected patients. Clin Ophthalmol. 2010;4:111-119.

9. Curran M, Noble S. Valganciclovir. Drugs. 2001;61(8):1145-1150; discussion 1151-1152.

10. Jung D, Dorr A. Single-dose pharmacokinetics of valganciclovir in HIV- and CMV-seropositive subjects. J Clin Pharmacol. 1999;39(8): 800-804.

11. Brown F, Banken L, Saywell K, Arum I. Pharmacokinetics of valganciclovir and ganciclovir following multiple oral dosages of valganciclovir in HIV- and CMV-seropositive volunteers. Clin Pharmacokinet. 1999;37(2):167-176.

12. Stavrou P, Deutsch J, Rene C, Laws DE, Luqmani RA, Murray PI. Ocular manifestations of classical and limited Wegener's granulomatosis. Q J Med. 1993;86(11):719-725.

13. Oktavec KC, Nolan K, Brown DM, Dunn JP, Livingston AG, Thorne JE. Clinical outcomes in patients with cytomegalovirus retinitis treated with ganciclovir implant. Am J Ophthalmol. January 19, 2012 [Epub ahead of print.]
Clinical Ophthalmology

\section{Publish your work in this journal}

Clinical Ophthalmology is an international, peer-reviewed journal covering all subspecialties within ophthalmology. Key topics include: Optometry; Visual science; Pharmacology and drug therapy in eye diseases; Basic Sciences; Primary and Secondary eye care; Patien Safety and Quality of Care Improvements. This journal is indexed on

Submit your manuscript here: http://www.dovepress.com/clinical-ophthalmology-journal

\section{Dovepress}

PubMed Central and CAS, and is the official journal of The Society of Clinical Ophthalmology (SCO). The manuscript management system is completely online and includes a very quick and fair peer-review system, which is all easy to use. Visit http://www.dovepress.com/ testimonials.php to read real quotes from published authors. 